\title{
Thermal Spray Coatings as an Adhesion Promoter in Metal/FRP Joints
}

\author{
Thomas Lindner*, Erik Saborowski, Mario Scholze, Benjamin Zillmann and Thomas Lampke \\ Materials and Surface Engineering Group, Institute of Materials Science and Engineering, Chemnitz University \\ of Technology, D-09107 Chemnitz, Germany; erik.saborowski@mb.tu-chemnitz.de (E.S.); \\ mario.scholze@mb.tu-chemnitz.de (M.S.); Benjamin.Zillmann@de.bosch.com (B.Z.); \\ thomas.lampke@mb.tu-chemnitz.de (T.L.) \\ * Correspondence: th.lindner@mb.tu-chemnitz.de; Tel.: +49-371-5313-8287
}

Received: 17 September 2018; Accepted: 25 September 2018; Published: 27 September 2018

\begin{abstract}
In this study, various structuring methods for creating adhesion by mechanical interlocking in the interface of metal/FRP (fiber-reinforced polymer) joints are investigated. A novel processing route using thermal spray coatings as additive structure is presented. Different coating systems are first assessed by axial loading tests with spray-coated plungers for the evaluation of the additive layer adhesion on the metallic base material. Additional microstructures, produced by different abrasive processes (corundum blasting, laser structuring, and fine milling) are compared with the additive structures. All surface structures are characterized by electron microscopy for two sheet materials: DC06 and AA6016-T4. The abrasive structures show a significant material dependence, while the selected coating system offers the adjustment to different base materials by an independent surface layer. The structured metal sheets were further joined to glass-fiber-reinforced polyamide 6 (PA6) by hot pressing to evaluate the interface properties in tensile shear tests. The results confirm a suitability of thermal spray coatings for providing a high bonding strength in metal/FRP joints for both investigated metallic substrate materials.
\end{abstract}

Keywords: hybrid joining; surface structuring; thermal spraying; coating; FRP; hot pressing; bonding strength; adhesion; mechanical interlocking

\section{Introduction}

Hybrid material compounds, consisting of metal and fiber-reinforced polymer (FRP), are very common for lightweight structures in the aviation field, as well as in the automotive industry, due to their high strength-to-weight ratio. A key challenge is the joining of those dissimilar materials, especially metal and polymer. Currently, hybrid material compounds are generated by

- adhesive bonds by Huang et al. [1],

- mechanical joints with rivets shown by Di Franco et al. [2] or bolts by Matsuzaki et al. [3],

- mechanical joining by plastic deformation of the metal and polymer partner (e.g., clinching showed by Lambiase and Di Ilio [4] and Friedrich et al. [5]),

- friction spot or lap welding by Amancio-Filho et al. [6] and Liu et al. [7],

- ultrasonic spot welding by Wagner et al. [8] and Mitschang et al. [9].

- direct joining by hot pressing with adhesion promoters by Yulinova et al. [10] and without by Sickert and Haberstroh [11], and

- laser-assisted joining by Katayama and Kawahito [12].

Adhesive bonding is the state of the art in joining metal and FRP. Huang et al. [13] studied adhesively bonded joints between aluminum and FRP, which resulted in low tensile shear strength 
$(\approx 4 \mathrm{MPa})$. Huang et al. [13] also applied a plastic deformation during the joining process, which improved the strength by about $17 \%$. Other studies by Velthuis et al. [14] and by Molitor and Young [15] showed that an adhesive bond, using advanced adhesive and an additional pretreatment of the surfaces, can reach a maximum tensile shear strength value of around $16 \mathrm{MPa}$. However, adhesively bonded joints are sensitive to several environmental conditions, like humidity (Lee et al. [16]), ultraviolet radiation (Nguyen et al. [17]) or variations in temperature (Nguyen et al. [18]). Mechanical joints with rivets or bolts increase the total weight due to the additional element. Furthermore, fibers are cut and exposed, which causes local stress concentrations that can lead to a premature failure of the component. Balle et al. [19] showed a very promising joining approach by ultrasonic spot welding. A maximum tensile shear strength of $23 \mathrm{MPa}$ between an aluminum sheet and a carbon-fiber-reinforced polymer was achieved by this technology. Mitschang et al. [9] used an induction spot welding technology and gained tensile shear strength, from $15 \mathrm{MPa}$ to $23 \mathrm{MPa}$, depending on the pretreatment of the metallic and polymer material. The method of friction lap welding was used for a hybrid aluminum-nylon join by Liu et al. [7], achieving a maximum tensile shear strength of 5-8 MPa. Sickert and Haberstroh [11] studied the process of direct joining of FRP to metal by hot pressing using multiple joining steps. A strength improvement of about $10 \%$ could be achieved with multiple joining steps and different pressures, compared to a constant pressure. Yulinova et al. [10] used twin polymers as an adhesion promoter on a non-treated metal surface in the hot joining process. The achieved maximum shear strength was $13 \mathrm{MPa}$, which was about $50 \%$ higher compared to the non-promoted corundum blasted surface.

Consequently, the achieved maximum strength is a function of the joining process itself. Furthermore, the surface preparation prior to the joining process has a huge influence on the final properties. Mitschang et al. [9] studied the joining strength by applying different pretreatments on the metallic and polymer partners. The pretreatment can be done by chemical, mechanical, or physical processes as listed by Velthuis et al. [14]. A major influence was found in using corundum blasting and acidic pickling, which increased the tensile shear strength by $60 \%$ compared to the other pretreatment steps. In general, the main goal of structuring the surface of the metal component are the increase in the surface area and the generation of undercuts for a mechanical clamping of the polymer. The corundum blasting can induce a certain amount of residual stresses in the material (Tosha and Iida [20]), causing deformations of thin-walled components. Another promising method is the mechanical structuring by using a laser showed by Schulze et al. [21]. The advantages are the high flexibility of the work piece geometry and process design, while area output is limited. The laser creates a microstructure with undercuts, which also allows a mechanical clamping of the dissimilar materials. Moreover, Roesner et al. [22] found an increase in tensile shear strength with a reduction of the laser line distance.

The present study introduces thermal spraying technology as a new process to create an advanced integration zone for metal/FRP joints. Thermal spray coatings can especially offer porous structures and high surface roughness. Consequently, a large specific surface area is achieved, which is beneficial for a higher joining strength. The thermal spray coatings are, furthermore, compared to three different abrasive mechanical structuring methods (corundum blasting, laser, and milling applications) in terms of the resulting strength between metal and FRP, as well as the microstructure of the integration zone after joining. The aim of this work is to produce an integration zone with high bonding strength and an easy implementation in an industrial environment.

\section{Materials and Methods}

\subsection{Materials Characterization}

The investigated hybrid metal/FRP compounds consist of a glass-fiber reinforced PA6 (2-layered with a $0^{\circ} / 90^{\circ}$ fiber orientation) connected to DC06 as a low carbon deep drawing steel and an AA6016-T4 aluminum alloy, respectively. The material properties are shown in Table 1. A differential scanning calorimetry (DSC) measurement of the FRP has been carried out for determining the process 
window for hot pressing of the compound. Figure 1 shows two endothermic peaks for the melting and decomposition temperatures of the PA6 at $496 \mathrm{~K}$ and $730 \mathrm{~K}$, respectively.

Table 1. Material properties.

\begin{tabular}{cccccc}
\hline Material & $\begin{array}{c}\text { Thickness } \\
\mathbf{( m m )}\end{array}$ & $\begin{array}{c}\text { Elongation to } \\
\text { Failure } \mathbf{( \% )}\end{array}$ & $\begin{array}{c}\text { Ultimate Strength } \\
\mathbf{( M P a )}\end{array}$ & $\begin{array}{c}\text { Yield Strength } \\
\mathbf{( M P a})\end{array}$ & $\begin{array}{c}\text { Hardness } \\
\mathbf{( H V ~ 1 0 )}\end{array}$ \\
\hline FRP & 2 & 0.9 & 440 & - & - \\
AA6016-T4 & 1 & 25 & 170 & 120 & 73 \\
DC06 & 1 & 50 & 270 & 160 & 84 \\
\hline
\end{tabular}

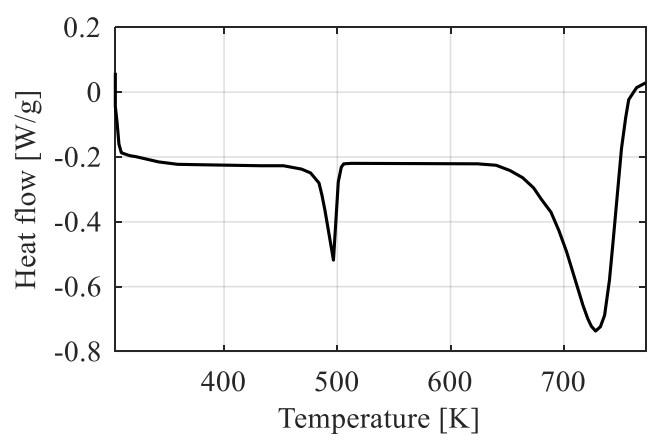

Figure 1. DSC measurement of the FRP with two endothermic peaks indicating the melting and decomposition temperatures.

\subsection{Surface Pretreatment}

For the specific design of an integration zone, a suitable surface treatment is necessary. During the conducted investigations, micro- and macrostructures were generated on the DC06 and AA6016-T4 surface. This leads to a higher specific surface area, and provides good conditions for an optimal mechanical interlocking of the PA6. Thermal spraying, corundum blasting, and laser structuring were chosen as microstructuring methods. The macrostructures were generated by milling. The corundum blasting was carried out with aluminum oxide EK-F-24 at a pressure of 2 bar with a blasting angle of $70^{\circ}$ and a distance of $200 \mathrm{~mm}$. Arc wire spraying has been chosen for the thermal spray coating process, due to its advantageous properties in terms of processability, productivity, and cost efficiency. The arc wire spray system VisuArc 350 (Sulzer, Winterthur, Switzerland) was used to apply the spray layers, Figure 2.

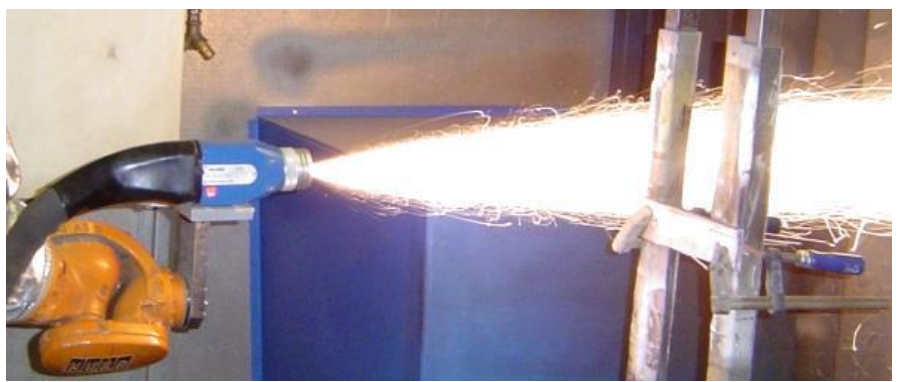

Figure 2. Sulzer VisuArc 350 arc wire spraying system.

NiAl5, NiAl20, and NiCr20 (cored wire thickness: $1.6 \mathrm{~mm}$ ) have been chosen as spraying materials, as these alloys are typical bond coat materials in thermal spraying, referring to Davis [23] and American Welding Society [24]. The used alloys, as well as the corresponding parameters of the thermal spraying process, can be seen in Table 2 . 
Table 2. Coating materials and parameters used for electric arc wire spraying.

\begin{tabular}{ccccccccc}
\hline Alloy & $\begin{array}{c}\text { Current } \\
(\mathbf{A})\end{array}$ & $\begin{array}{c}\text { Voltage } \\
(\mathbf{V})\end{array}$ & $\begin{array}{c}\text { Feed } \\
\text { Velocity } \\
(\mathbf{m} / \mathbf{s})\end{array}$ & $\begin{array}{c}\text { Spraying } \\
\text { Distance } \\
(\mathbf{m m})\end{array}$ & $\begin{array}{c}\text { Air } \\
\text { Pressure } \\
(\mathbf{b a r})\end{array}$ & $\begin{array}{c}\text { Line } \\
\text { Distance } \\
(\mathbf{m m})\end{array}$ & $\begin{array}{c}\text { Growth } \\
\text { by Step } \\
(\boldsymbol{\mu m})\end{array}$ & $\begin{array}{c}\text { Thermal } \\
\text { Expansion } \\
\left(\mathbf{( 1 0}^{-\mathbf{6}} \mathbf{K}^{-\mathbf{1}} \mathbf{)}\right.\end{array}$ \\
\hline $\mathrm{NiAl5}$ & 200 & 25 & 1.0 & 130 & 3.5 & 5 & 50 & 13.9 \\
$\mathrm{NiAl20}$ & 200 & 25 & 1.0 & 130 & 3.5 & 5 & 50 & 15.3 \\
$\mathrm{NiCr} 20$ & 240 & 24 & 1.0 & 130 & 3.5 & 5 & 40 & 11.7 \\
\hline
\end{tabular}

A fiber laser (ytterbium, wavelength: $1064 \mathrm{~nm}$ ) was used for laser structuring the metallic joining partners. The laser parameters (Table 3) had to be adjusted to the different materials, due to the lower absorption coefficient of the aluminum, which results in a lower coupling of the laser beam and an associated restriction of the processing options.

Table 3. Parameters for laser structuring depending on the used materials.

\begin{tabular}{ccccccc}
\hline Material & Power $(\mathbf{W})$ & $\begin{array}{c}\text { Velocity } \\
(\mathbf{m m} / \mathbf{m i n})\end{array}$ & $\begin{array}{c}\text { Pulse Width } \\
(\mathbf{n s})\end{array}$ & Spot $(\boldsymbol{\mu m})$ & $\begin{array}{c}\text { Line Distance } \\
(\boldsymbol{\mu m})\end{array}$ & $\begin{array}{c}\text { Penetration } \\
\text { Depth }(\boldsymbol{\mu m})\end{array}$ \\
\hline AA6016-T4 & 1300 & 150 & 200 & 50 & 250 & $20-50$ \\
DC06 & 1800 & 200 & 200 & 50 & 500 & $75-90$ \\
\hline
\end{tabular}

The macrostructures were produced by milling. The cutting speed was set to $150 \mathrm{~m} / \mathrm{min}$, and the feed speed to $0.3 \mathrm{~mm} /$ tooth. The resulting macrostructure consists of pyramid-shaped elements with a height of $0.5 \mathrm{~mm}$ and an angle of $45^{\circ}$.

Additionally, the surface roughness was measured by tactile incision technique using a T8000 system (Hommel-Etamic, Jena, Germany). All measurements were performed with a TKU300 tip using uniform parameters for all structures (measurement length $=1.5 \mathrm{~mm}$, velocity $=0.5 \mathrm{~mm} / \mathrm{s}$, point distance $=0.5 \mu \mathrm{m})$.

\subsection{Mechanical Testing of Adhesive Strength}

Axial loading tests according to DIN EN 582 for the preselection of the spray system were performed utilizing adhesive pads FM1000 (Cytec Solvey Group, Woodland Park, CO, USA) in combination with the spray-coated metal plungers (Figure $3 \mathrm{a}$ ). The specimens were joined to the adhesion pads by hot pressing. Metal plungers with a length of $50 \mathrm{~mm}$ and a diameter of $25 \mathrm{~mm}$ were used. During the joining process for the axial loading tests, the samples were treated at $473 \mathrm{~K}$ and fixed for a constant joining pressure in a preheated furnace for $90 \mathrm{~min}$. Afterwards, cooling down was conducted directly in the furnace for approximately $300 \mathrm{~min}$. After preselection of the coating system, the feedstock material was applied to the plungers of both metallic materials, DC06, and AA6016-T4. Furthermore, the bonding strength was examined in dependency of the pretreatment state of the surface using FRP as a joining partner (Figure $3 b$ ).
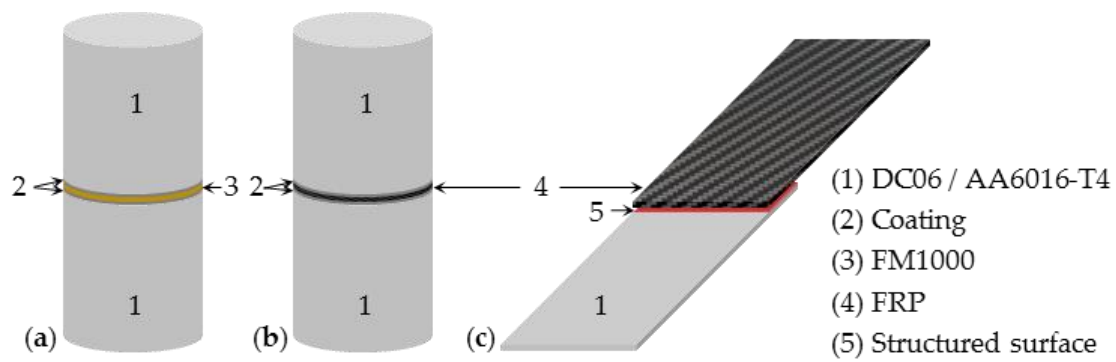

Figure 3. Setup for evaluating (a) the axial bonding strength of the thermal spray coating to the metal sheet; (b) between the coating and the FRP; and (c) the tensile shear strength of different surface structures to the FRP. 
In order to optimize the joining process, the two plungers were inductively heated to $558 \mathrm{~K}$ within $20 \mathrm{~s}$, followed by insertion of the FRP between the plungers and applying a joining pressure of $0.3 \mathrm{MPa}$. As a result of the optimized joining process, the samples are completely cooled down within $5 \mathrm{~min}$. Axial loading tests were performed at $1 \mathrm{~mm} / \mathrm{min}$ traverse speed in a tensile testing machine with a standard load cell Z020 (Zwick/Roell, Ulm, Germany). The bonding strength was determined using the calculated circular contact area of $491 \mathrm{~mm}^{2}$.

Tensile shear tests were carried out in accordance to DIN EN 1465 to evaluate the shear strength of a single lap joint, Figure 3c. Metal and FRP stripes with a length of $100 \mathrm{~mm}$ and a width of $25 \mathrm{~mm}$ were bonded to each other with an overlapping length of $5 \mathrm{~mm}$. In contrast to the standardized geometry, the overlap length was reduced from $12.5 \mathrm{~mm}$ to $5 \mathrm{~mm}$, in order to enable a meaningful testing of high shear strength, due to a more homogeneous stress distribution among the interface (Saborowski et al. [25]). For tensile shear strength testing, the specimens were produced utilizing a die heating process (see Figure $4 \mathrm{a}$ for the lap shear specimen production tool). According to the production parameters determined by Haberstroh and Sickert [26], a joining pressure of $0.3 \mathrm{MPa}$ and a maximum joining temperature of $558 \mathrm{~K}$ were chosen. During the joining process, the die is heated until the maximum joining temperature inside of the integration zone is reached, and immediately afterwards cooled down via an air-cooling system until the temperature drops below $373 \mathrm{~K}$ (Figure 4b). The pressure is maintained constant over the whole production time to prevent the formation of cavities in the polymer during the cooling process (Flock [27]). The temperature in the integration zone is observed by a thermocouple placed inside a drill-hole slightly below the metal surface. Finally, the specimens were tested in a tensile testing machine Z020 (Zwick/Roell, Ulm, Germany) under a constant crosshead speed of $1 \mathrm{~mm} / \mathrm{min}$. The tensile shear strength was determined using the nominal value of the rectangular contact area of $125 \mathrm{~mm}^{2}$.

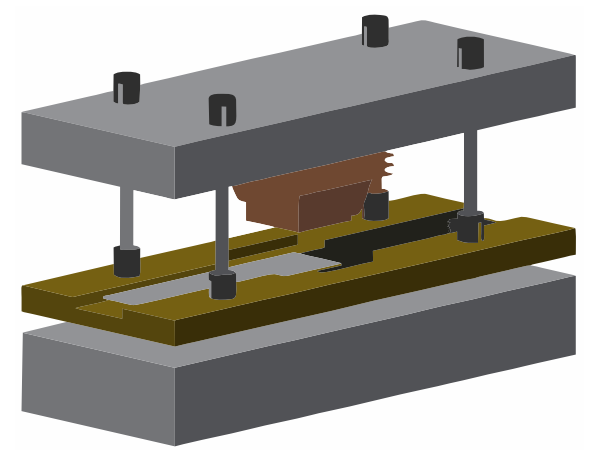

(a)

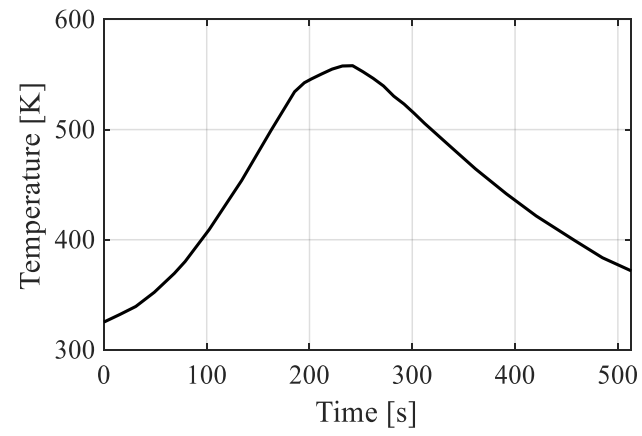

(b)

Figure 4. Joining fixture and temperature profile. (a) Apparatus with a heatable die for the production of tensile shear specimens; (b) Temperature inside the joining zone during the hot pressing process.

\section{Results and Discussion}

\subsection{Preselection of Thermal Spray Coating Material}

To choose a suitable thermal spray feedstock material, the adhesion between the coating materials and the DC06 plunger was investigated, Table 2. The coating thickness as well as the surface pretreatment were investigated, Figure 5a. The lowest coating thickness, in combination with the corundum-blasted surface, indicates the highest bonding strength (about $60 \mathrm{MPa}$ ), which is independent of the coating material. Moreover, the bonding strength decreases with increasing layer thickness.

NiCr20 shows a drop of only $25 \%$ when comparing the bonding strength at $40 \mu \mathrm{m}$ and $320 \mu \mathrm{m}$ coating thickness. The pretreatment of surface strongly affects the achievable bonding strength. A non-blasted surface state reduces the bonding strength, since the mechanical interlocking between 
the substrate and coating material is less pronounced. The achieved higher values for NiAl5 can be explained by micro metallurgical bonding resulting from the exothermic reaction between the alloy components [28]. The determined bonding strength of the coatings, with the exception of NiCr20 by non-blasted substrate, were far above $25 \mathrm{MPa}$. The high adhesion strength of the spray coatings is one of the key requirements for the suitability of thermal spray coatings as an adhesion promoter in metal/FRP compounds. For all further experiments, NiAl5 was chosen as suitable representative material for this feedstock class.

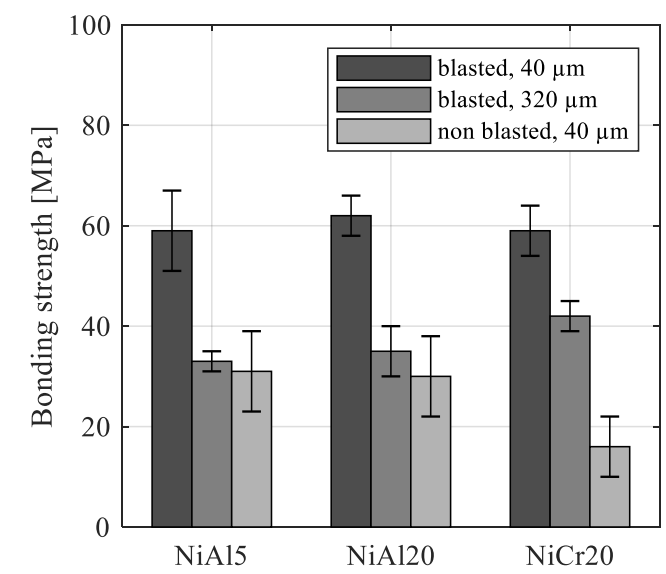

(a)

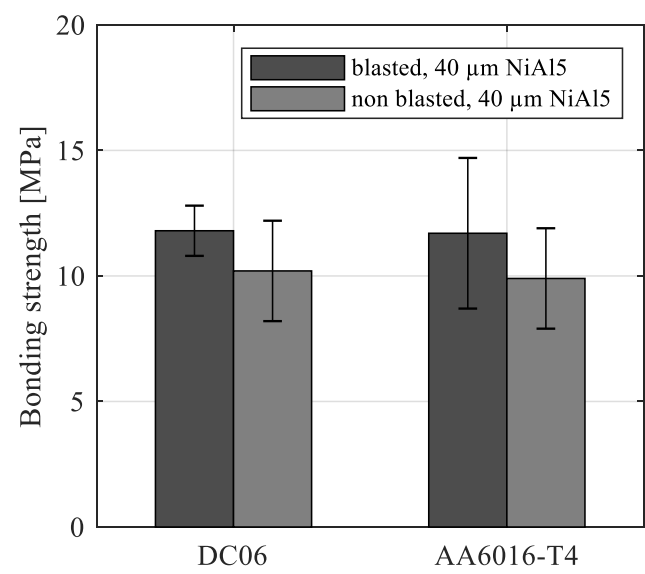

(b)

Figure 5. Bonding strength under axial tension (a) thermal spray layer to DC06 substrate; (b) FRP to thermal spray layer (NiAl5).

The results for the specimen with FRP as joining partner are presented in Figure $5 \mathrm{~b}$. The tensile strength is in a range of 10-12 MPa for both metallic plunger materials. A roughening of the surface by corundum blasting only affects the bonding strength insignificantly. Consequently, it is appropriate to apply the thermal spray coating to the non-blasted surface.

\subsection{Characterization of Structured Metal Surfaces}

Scanning electron microscope (SEM) surface images for the two sheet materials are shown in Figure 6. The corundum blasted surfaces exhibit a random distribution of the surface structure with $R_{\mathrm{z}}$ $=36 \mu \mathrm{m}$, whereby the aluminum material shows a higher roughness $\left(R_{\mathrm{z}}=81 \mu \mathrm{m}\right)$ because of its lower hardness. The surface structure of the NiAl5 coating offers similar surface characteristics for both substrate materials. The surface roughness is randomly distributed and has similar peak values (DC06 NiAl5: $R_{\mathrm{Z}}=85 \mu \mathrm{m}, \mathrm{Al6016}-\mathrm{T} 4 \mathrm{NiAl5}: 88 \mu \mathrm{m}$ ) compared to the corundum-blasted AA6016-T4. The laser structured surfaces show a homogenous grid with height peaks of about $80 \mu \mathrm{m}$ for DC06, and $20 \mu \mathrm{m}$ for the aluminum material. Additionally, the edges are covered by melted substrate material, which increases the specific surface area again. The differences in the laser structure of DC06 and AA6016-T4 are presumably caused by different absorption coefficients. The milled surfaces exhibit pyramidal structures. Comparing the different milled surfaces, a homogeneous structure was achieved in case of AA6016-T4, while DC06 shows several residues, which could, for example, promote better mechanical clamping to FRP. In summary, a considerable number of undercuts, as well as a high specific surface area, ensures sufficient potential for a high joining strength between metal and FRP. 
DC06 laser

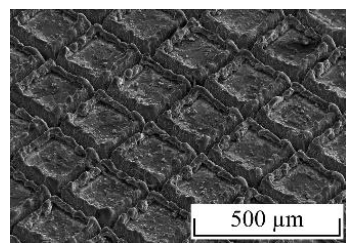

DC06 blasted

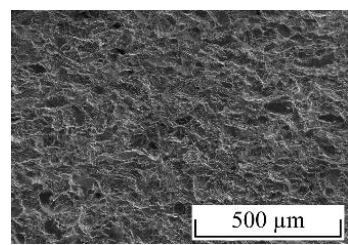

AA6016-T4 laser

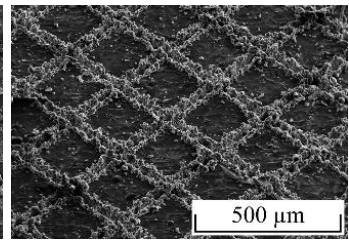

AA6016-T4 blasted

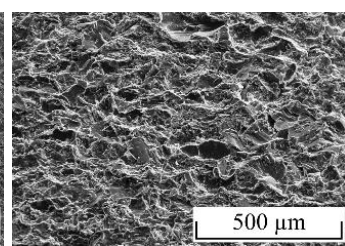

DC06 milling

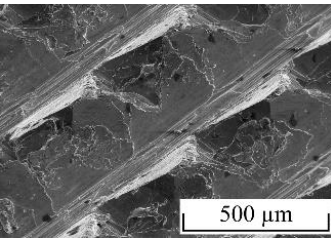

AA6016-T4 NiAl5

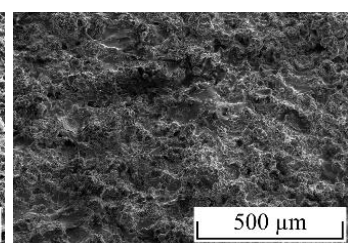

AA6016-T4 milling

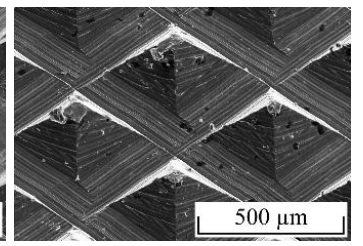

DC06 NiAl5

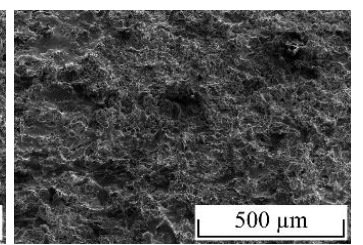

Figure 6. SEM images of the differently structured surfaces for DC06 and AA6016-T4.

\subsection{Tensile Shear Properties of FRP/Metal Joints}

Figure 7 shows the results of the tensile shear tests for the metal/FRP specimens with the differently structured metal surfaces. There is a significant influence of the surface pretreatment on the shear strength. The most promising methods in terms of high shear strength are laser treatment and the thermally sprayed NiAl5 coating. Thermal spraying ensures mechanical clamping by several undercuts, and reduces the influence of the substrate material through adjustment of the coating material.

Consequently, a high bonding strength between the metallic sheet and FRP is ensured. The corundum blasting and milling treatments show significant differences in surface structures as well as in the resulting shear strength, depending on the used sheet material. When comparing the surface topography (Figure 6) of the different structures with the bonding strength, assessment of the determined bonding strength becomes possible. Corundum blasting of AA6016-T4 results in a higher roughness in contrast to DC06. By using equal parameter conditions, the relatively soft aluminum substrate shows a significantly higher abrasive effect than steel. The higher roughness is presumably the main reason for the higher bonding strength caused by enhanced mechanical interlocking of the polymer melt. Laser structuring shows only a minor material influence and a good mechanical clamping is provided in tensile shear testing. The resulting structure using the milling process differs significantly between steel and aluminum. A high number of slats in the pre-milled lines of the DC06 substrate builds undercuts for the polymer melt. AA6016-T4 does not show such structures, while shear strength is the lowest of all compared structures.

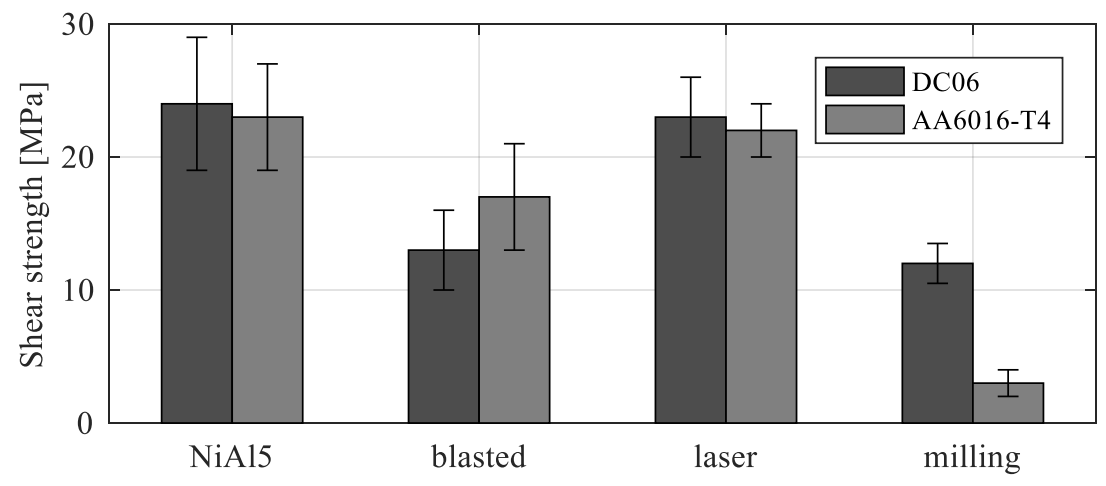

Figure 7. Tensile shear strength of metal/FRP specimen joined by die heating. 
Presumably, the main influence on bonding strength of the investigated structures is mechanical clamping. A combination of undercuts and randomized surface structures with a certain roughness lead, especially in the case of spray coated and laser structured interfaces, to high values in bonding strength. When comparing the time of manufacturing for a specific surface area, the potential of thermal spray coating becomes obvious. While laser structuring offers approximately the same interface strength, the required manufacturing time for these abrasive structures is significantly higher. Considering the differences in processing parameters used in this study (which depend on the treated metal sheet) e.g., velocity, line distance and the additional secondary overrun (rotated under $90^{\circ}$ ), laser structuring takes about 6000-16,000 times longer for the same specific surface area in comparison to thermal spraying. Furthermore, processing parameters for all abrasive treatments, including laser structuring, need to be adjusted in a complex way when changing the type of base material. In contrast, thermal spraying delivers a reproducible and similar bonding strength for different substrate materials and the combination of different materials for FRP/metal compounds is facilitated.

\section{Conclusions}

An experimental study of different surface structuring methods as adhesion promoter for joining hybrid metal/FRP compounds has been carried out in this work. Thermal spray technology is presented as a new approach for additive structuring of the metallic surface.

$\mathrm{NiAl} 5$ as feedstock material exhibits a good adhesion even on smooth metallic surfaces. A material adjustment is implemented by the coating, which provides a similar bonding strength in metal/FRP compounds regardless of the metallic part. Especially, the high surface roughness with undercuts is suitable for mechanical clamping. With a shear strength of $23-24 \mathrm{MPa}$, the thermal spray coating achieved the best results of all presented structuring methods. Laser structuring showed similarly good results $(-4.2 \%$ DC06/ $-4.3 \%$ AA6016-T4), whereas corundum blasting achieves a considerably lower adhesion $(-45.8 \%$ DC06/ $-29.2 \%$ AA6016-T4) and the investigated milling structure is not useful at all (-51.1\% DC06/-87.0\% AA6016-T4). Taking into account the different surface topographies, the results can be explained in the following way:

- The adhesion is mainly achieved by mechanical clamping when just using a structured surface without chemical adhesion promoters

- A surface profile containing a considerable number of undercuts delivers the best results

- The bonding strength is not influenced by the substrate material when using thermal spraying due to the almost identical surface characteristics

- The time for manufacturing the surface structure is significantly reduced when using thermal spraying in comparison to laser structuring

Author Contributions: Thomas Lindner and Benjamin Zillmann planned and designed the experiments. Benjamin Zillmann, Thomas Lindner, Erik Saborowski and Mario Scholze conducted the experiments, analysed the data and drafted the manuscript. Thomas Lampke directed the research and contributed to the discussion and interpretation of the results.

Funding: This study was supported by the Federal Cluster of Excellence EXC 1075 'MERGE Technologies for Multifunctional Lightweight Structures'. Funding by the German Research Foundation (Deutsche Forschungsgemeinschaft, DFG), Germany is gratefully acknowledged.

Conflicts of Interest: The authors declare no conflict of interest.

\section{References}

1. Huang, Z.; Sugiyama, S.; Yanagimoto, J. Hybrid joining process for carbon fiber reinforced thermosetting plastic and metallic thin sheets by chemical bonding and plastic deformation. J. Mater. Process. Technol. 2013, 213, 1864-1874. [CrossRef]

2. Di Franco, G.; Fratini, L.; Pasta, A. Analysis of the mechanical performance of hybrid (SPR/bonded) single-lap joints between CFRP panels and aluminum blanks. Int. J. Adhes. Adhes. 2013, 41, 24-32. [CrossRef] 
3. Matsuzaki, R.; Shibata, M.; Todoroki, A. Improving performance of GFRP/aluminum single lap joints using bolted/co-cured hybrid method. Compos. Part A Appl. Sci. Manuf. 2008, 39, 154-163. [CrossRef]

4. Lambiase, F.; Di Ilio, A. Mechanical clinching of metal-polymer joints. J. Mater. Process. Technol. 2015, 215, 12-19. [CrossRef]

5. Friedrich, S.; Georgi, W.; Gehde, M.; Mayer, P. Hybrid joining technology-A new method for joining thermoplastic-metal-mixed components. AIP Conf. Proc. 2014, 1593, 121-127.

6. Amancio-Filho, S.T.; Bueno, C.; dos Santos, J.F.; Huber, N.; Hage, E., Jr. On the feasibility of friction spot joining in magnesium/fiber-reinforced polymer composite hybrid structures. Mater. Sci. Eng. 2011, 528, 3841-3848. [CrossRef]

7. Liu, F.; Liao, J.; Nakata, K. Joining of metal to plastic using friction lap welding. Mater. Des. 2014, 54, $236-244$. [CrossRef]

8. Mitschang, P.; Velthuis, R.; Didi, M. Induction spot welding of metal/CFRPC hybrid joints. Adv. Eng. Mater. 2013, 15, 804-813. [CrossRef]

9. Wagner, G.; Balle, F.; Eifler, D. Ultrasonic welding of aluminum alloys to fiber reinforced polymers. Adv. Eng. Mater. 2013, 15, 792-803. [CrossRef]

10. Yulinova, A.; Göring, M.; Nickel, D.; Spange, S.; Lampke, T. Novel adhesion promoter for metalplastic composites. Adv. Eng. Mater. 2015, 17, 802-809. [CrossRef]

11. Sickert, M.; Haberstroh, E. Thermal direct joining for hybrid plastic metal structures. In Proceedings of the Euro Hybrid Materials and Structures, Stade, Germany, 10-11 April 2014; pp. 42-45.

12. Katayama, S.K.Y. Laser direct joining of metal and plastic. Scr. Mater. 2008, 59, 1247-1250. [CrossRef]

13. Huang, Z.; Sugiyama, S.; Yanagimoto, J. Applicability of adhesive embossing hybrid joining process to glass-fiber-reinforced plastic and metallic thin sheets. J. Mater. Process. Technol. 2014, 214, 2018-2028. [CrossRef]

14. Velthuis, R.; Kotter, M.; Geiss, P.L.; Mitschang, P.; Schlarb, A.K. Lightweight structures made of metal and fiber-reinforced polymers. Kunststoffe Int. 2007, 11, 22-24.

15. Molitor, P.; Young, T. Adhesives bonding of a titanium alloy to a glass fibre reinforced composite material. Int. J. Adhes. Adhes. 2002, 22, 101-107. [CrossRef]

16. Lee, D.G.; Kwon, J.W.; Cho, D.H. Hygrothermal effects on the strength of adhesively bonded joints. J. Adhes. Sci. Technol. 1998, 12, 1253-1275.

17. Nguyen, T.; Bai, Y.; Zhao, X.; Al-Mahaidi, R. Effects of ultraviolet radiation and associated elevated temperature on mechanical performance of steel/CFRP double strap joints. Compos. Struct. 2012, 94, 3563-3573. [CrossRef]

18. Nguyen, T.; Bai, Y.; Al-Mahaidi, R.; Zhao, X. Time-dependent behaviour of steel/CFRP double strap joints subjected to combined thermal and mechanical loading. Compos. Struct. 2012, 94, 1826-1833. [CrossRef]

19. Balle, F.; Wagner, G.; Eifler, D. Ultrasonic spot welding of aluminum sheet/carbon fiber reinforced polymer joints. Mater. Und Werkst. 2007, 38, 934-938. [CrossRef]

20. Tosha, K.; Iida, K. Residual stress on the grit blasted surface. Metal Behav. Surf. Eng. 1989, 323-328. Available online: https://www.researchgate.net/profile/Katsuji_Tosha/publication/266463084_Residual_Stress_ on_the_Grit_Blasted_Surface/links/563c0c5b08ae405111a78398/Residual-Stress-on-the-Grit-BlastedSurface.pdf (accessed on 26 September 2018).

21. Schulze, K.; Hausmann, J.; Wielage, B. The stability of different titanium-peek interfaces against water. Procedia Mater. Sci. 2013, 2, 92-202. [CrossRef]

22. Roesner, A.; Olowinsky, A.; Gillner, A. Long term stability of laser joined plastic metal parts. Phys. Procedia 2013, 41, 169-171. [CrossRef]

23. Davis, J.R. Handbook of Thermal Spray Technology; ASM International: Russell Township, OH, USA, 2004.

24. American Welding Society. Thermal Spraying: Practice, Theory, and Application; American Welding Society: Miami, FL, USA, 1985.

25. Saborowski, E.; Scholze, M.; Lindner, T.; Lampke, T. A numerical and experimental comparison of test methods for the shear strength in hybrid metal/thermoplastic-compounds. IOP Conf. Ser. Mater. Sci. Eng. 2017, 181, 012031. [CrossRef]

26. Haberstroh, E.; Sickert, M. Thermal Direct Joining of Hybrid Plastic Metal Components. KMUTNB Int. J. Appl. Sci. Technol. 2014, 7, 29-34. [CrossRef] 
27. Flock, D. Heat Conduction Bonding of Plastic-Metal Hybrid Parts; RWTH Aachen: Aachen, Germany, 2011; pp. 81-86.

28. Sheppard, J.A. Sprayed coatings of exothermically formed nickel aluminide. Br. Weld. J. 1963, 3, $603-606$.

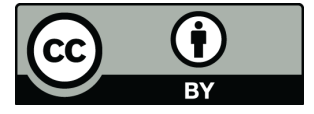

(C) 2018 by the authors. Licensee MDPI, Basel, Switzerland. This article is an open access article distributed under the terms and conditions of the Creative Commons Attribution (CC BY) license (http://creativecommons.org/licenses/by/4.0/). 